\title{
UMA PERSPETIVA SOBRE ALVES DOS SANTOS (1866-1924): APROPRIAÇÃO E DIFUSÃO DE IDEIAS PEDAGÓGICAS EM PORTUGAL
}

\author{
Helder Henriques ${ }^{1}$ \\ www.degois.pt/visualizador/curriculum.jsp?key=9310452499940096 \\ Amélia de Jesus Marchão² \\ www.ipportalegre.pt
}

\begin{abstract}
Resumo: Este trabalho discute a importância da circulação de ideias através das viagens pedagógicas ancorados no exemplo do lente da Universidade de Coimbra Augusto Joaquim Alves dos Santos (1866-1924). Procuramos discutir teoricamente o quadro político e pedagógico em que se desenvolveu a ação deste professor com relevo para a $1^{\text {a }}$ República Portuguesa (1910-1926). Depois, fazemos uma breve incursão pela sua vida académica e profissional e, por fim, dedicamos especial atenção ao seu pensamento pedagógico. A metodologia de análise é de tipo qualitativo, com recurso à análise de conteúdo. Utilizamos, principalmente, um corpus documental baseado nas obras do próprio professor. Em suma, defendemos que Alves dos Santos encontrou no quadro político republicano o espaço ideal para tentar concretizar um projeto pedagógico nacional cujo fundamento se encontra, sobretudo, relacionado com uma viagem que realizou à Suíça e à França.
\end{abstract}

Palavras-chave: Pedagogia; Alves dos Santos; Educação Nova; $1^{\mathrm{a}}$ República Portuguesa; Portugal.

\section{A PERSPECTIVE ABOUT ALVES DOS SANTOS (1866-1924): APPROPRIATION AND DIFFUSION OF PEDAGOGICAL IDEAS IN PORTUGAL}

\begin{abstract}
This work discusses the importance of the circulation of ideas through pedagogical trips anchored in the example of the lens of the University of Coimbra Augusto Joaquim Alves dos Santos (1866-1924). We try to discuss theoretically the political and pedagogical framework in which this teacher's action developed with emphasis on the 1st Portuguese Republic. Then we make a brief foray into his aca-

\footnotetext{
${ }^{1}$ Doutor em Ciências da Educação. Docente do Instituto Politécnico de Portalegre (Portugal). Contato: helderhenriques@esep.pt.

2 Doutora em Ciências da Educação. Docente do Instituto Politécnico de Portalegre (Portugal).Contato: ameliamarchao@esep.pt.
} 
demic and professional life and, finally, we pay special attention to his pedagogical thinking. The methodology of analysis is qualitative, using content analysis. We mainly use a documentary corpus based on the works of Professor Alves dos Santos. In short, we argue that Alves dos Santos found in the republican political framework the ideal space to try to materialize a national pedagogical project whose foundation is mainly related to a trip he made to Switzerland and France.

Keywords: Pedagogy; Alves dos Santos; New Education; 1st Portuguese Republic; Portugal.

\section{Introdução}

A circulação, apropriação e difusão de ideias pedagógicas tem merecido destaque no quadro da História da Educação Luso-Brasileira. O propósito do presente texto ancora-se na possibilidade de reforçar a importância do estudo da pedagogia através de um olhar externalizado onde se valorizam os contatos com diversos atores, as influências dos mesmos nos contextos nacionais e/ou a criação de redes de trabalho com vista ao desenvolvimento e aplicação de princípios ou movimentos pedagógicos. A partir deste pressuposto escolhemos como objeto de estudo um ator pedagógico fundamental à compreensão da História da Educação portuguesa nos primeiros decénios da centúria de novecentos: Augusto Joaquim Alves dos Santos (1866-1924). Deste modo, colocamos um conjunto de questões orientadoras à construção do trabalho: Quem é Alves dos Santos? Qual o seu papel na valorização das Ciências da Educação? Que influências pedagógicas assumiu? Como se apropriou das mesmas? E, de que modo as procurou difundir? A procura de resposta para este conjunto de questões de partida obrigou a uma revisão da literatura onde salientamos, entre outros, os trabalhos de Nóvoa, Carvalho, Correia, Madeira \& Ó (2003), relacionados com a circulação do conhecimento e a possibilidade de governação do indivíduo; Figueira (2004) que procura realçar a importância do movimento da Educação Nova e destaca a circulação de ideias pedagógicas; Gondra (2010), Silva (2012) e Gondra \& Mignot (2007) valorizam as viagens e itinerários 
pedagógicos de diferentes atores, entre eles os professores; ou, ainda, Nóvoa \& Schriewer (2000) que nos falam da pedagogia como elemento "universalista". Ao longo do texto incluiremos outros autores de referência relacionados com as linhas de análise agora identificadas (FERNANDES, 1979; ABREU, 1991; FERNANDES, 1993; GARRIDO, 1998; PINTASSILGO, 2007).

Do ponto de vista empírico, constituímos dois núcleos documentais: a legislação (1911) e as obras do professor Alves dos Santos (entre outras, 1915; 1919; 1923). Destacamos, em relação ao primeiro núcleo, um decreto-lei de 1911; e, em relação ao segundo núcleo, emergem com maior importância as obras de Alves dos Santos publicadas no período da $1^{\text {a }}$ República Portuguesa (1910-1926) sem, no entanto, esquecer o período anterior.

A abordagem metodológica pode se caraterizar como uma análise qualitativa, com destaque para a análise de conteúdo, onde se definiram as questões de partida, construiu-se um quadro teórico que permitiu a revisão da literatura e, depois, avançou-se para o trabalho de identificação da obra de Alves dos Santos, procedeu-se à recolha dos mesmos na Biblioteca Geral da Universidade de Coimbra e, finalmente, construiu-se uma análise cruzada sobre o itinerário de vida deste professor com particular centralidade para as problemáticas educativas e pedagógicas.

Em suma, defendemos que Alves dos Santos encontrou no enquadramento político da $1^{\text {a }}$ República Portuguesa o espaço ideal para cruzar os novos desígnios republicanos de construção de uma sociedade diferente da anterior, com os princípios do movimento da Educação Nova, que aprofundou no estrangeiro, contribuindo, desse modo, para uma maior compreensão da criança e valorização da educação nos processos de mudança que ele defendia.

\section{A Escola Nova, a $1^{\text {a }}$ República Portuguesa e os viajantes pedagógicos}


Ao longo da modernidade, o interesse do Estado pela qualidade da população objetivou-se nos espaços escolares que foram gradualmente "povoados" por especialistas e conhecimentos diversos, entre eles os psicólogos e/ou os saberes «psi». Estes espaços onde circulavam crianças e jovens constituíram parte fundamental da construção de um amplo projeto político que pretendia atingir o indivíduo e promover a sua governação. Contribuíram para este projeto a emergência das Ciências Sociais, nomeadamente a Psicologia e a Sociologia, que corresponderam ao desígnio estatal de normalização social e, por outro lado, potenciaram a emergência e identificação/categorização de diversas crianças e jovens, sobretudo daquelas que fugiam à normalidade.

Deste modo, procurou-se aprofundar o olhar sobre a criança - o seu corpo e a mente - com o objetivo de favorecer a autonomia do indivíduo e a sua moralização. Como afirmam Nóvoa, Carvalho, Correia, Madeira \& Ó (2003, p. 23) "we believe that the development of pedagogy, or the science of education, was motivated by the ambition to act and to govern the spirit and body of children and the young". Para alcançar o objetivo de governar o espírito e o corpo da criança e/ou jovem era necessário "cientificar" a pedagogia e encontrar metodologias e instrumentos capazes de produzir informação de modo a regular a sociedade logo a partir da infância e/ou juventude. A observação constituiu, neste contexto, um elemento central no processo de moralização do indíviduo e estudo do seu corpo. Como salientam Nóvoa et al. (2003, p. 24):

In fact, modern pedagogy refers often to the idea that there is a causal link between particularized knowledge of trends, habits, desires and emotions of the pupils, and the molding of their moral sensibility. It was the attempt to make this socializing technology viable and disciplined that was at the origin of the discovery of the pupil (...).

Esta “descoberta” da criança decorreu de uma aproximação conveniente entre a Pedagogia, a Psicologia e, mais tarde, a Sociologia. Com efeito, na transição do século XIX para o século XX, o processo de cientificação da pedagogia constituiu um dos aspetos mais relevantes no 
quadro da afirmação da(s) ciência(s) da educação. Nóvoa (1994, p. 17), inspirado em Charbonnel (1988), carateriza este processo em duas fases: a fase Compayré e a fase da pedagogia experimental. Para o autor, a $1^{\mathrm{a}}$ fase corresponde às décadas finais do século XIX onde se assistiu à valorização institucional da educação pelo fato de poder ser ensinada. A $2^{\mathrm{O}}$ fase, associada às primeiras décadas de novecentos, pode ser caraterizada pela emergência da psicologia na relação com a pedagogia. O que marca este tempo de mudança, na transição entre centúrias, é a busca de fundamento científico, pela pedagogia, através da psicologia, e toda uma nova visão relacionada com a arena educativa e, em particular, o corpo e mente da criança.

É neste contexto de valorização do individuo (Self) e da sua experiência e também de interesses coletivos e estatais que emerge a Escola Nova. Este movimento pedagógico colocou centralidade e singularidade sobre a criança e/ou jovem e deu primazia a práticas pedagógicas inovadoras que visavam agir sobre o corpo e a mente do sujeito. Genericamente, pode se caraterizar pela existência de dois eixos: 1) Compreensão da criança; 2) Inovação educativa (FIGUEIRA, 2004, p. 28). Destes dois eixos, entre outros, destacamos a emergência da psicologia que permitiu uma “(...) alteração radical do olhar sobre a criança (...)” (FIGUEIRA, 2004, p. 29) implicando alterações significativas nas escolas e a emergência de instituições escolares que procuravam contrariar o sentido tradicional da educação3. O objetivo maior era promover uma formação completa da criança uma vez que esta representava o futuro da sociedade. Tal como Figueira (2004, p. 34) realça:

O mais importante dessa marca [Escola Nova] consiste no espírito de abertura para com a criança e na tentativa da sua compreensão, na atitude de inconformismo em relação às práticas pedagógicas rotineiras, no desejo de instaurar na sala de aula e no ambiente escolar em geral um clima de amizade e de confiança reciprocas entre alunos e professores.

3 É o caso da Escola-Oficina $n^{0} 1$ ou, mais tarde, da Escola Nova fundada na Bélgica pelo português Faria de Vasconcelos. 
Em Portugal, o movimento pedagógico referido encontrou um contexto político que favoreceu a sua difusão, na medida em que ajudava a fundamentar as opções políticas. Estamos a referir-nos, em particular, ao regime republicano português $-1^{\mathrm{a}}$ República (1910-1926) - que afirmou pretender tornar a escola, e portanto a Educação, num elemento central da política procurando, através da arena educativa, formar um homem novo, crítico, capaz de refletir e promover ideais cívicos e o próprio regime republicano. A publicação da Reforma do Ensino Infantil, Primário e Normal ( de 29 de Março de 1911) representou bem os propósitos do novo regime político português na relação com a educação quando o legislador afirmava:

Educar uma sociedade é fazê-la progredir, torná-la um conjunto harmónico e conjugado das forças individuais, por seu turno desenvolvidas em toda a sua plenitude. E só se pode fazer progredir e desenvolver uma sociedade, fazendo com que a ação contínua, incessante e persistente da educação, atinja o ser humano, sob o tríplice aspeto: físico, intelectual e moral. (Portugal, 29 de Março de 1911).

Como evidencia a citação anterior, o regime republicano português coincidiu com o movimento pedagógico da Escola Nova no propósito de transformar a sociedade, recorrendo a uma educação integral. É neste contexto que se afirma a necessidade de "fazer cidadãos" que transformassem Portugal numa "colmeia humana, laboriosa e pacífica" (idem). Também neste aspeto, o regime republicano, embora isso já acontecesse anteriormente como assinala Pintassilgo (2007), coincidiu com o movimento pedagógico, na medida em que impulsionou um conjunto de educadores a conhecer o que se fazia no estrangeiro, do ponto de vista educacional, e a importar/adaptar essas ideias para o contexto nacional.

As viagens assumiram um papel relevante no processo de circulação, apropriação e difusão do conhecimento pedagógico. Como defende Gondra (2010, p. 13), "as viagens dos educadores funcionam como técnica de investigação e de conhecimento, como prática de observar, experimentar, comparar e produzir conhecimento sobre o 
outro". Este conhecimento experienciado assumiu um sentido "universalista" na medida em que percorreu e inspirou várias realidades nacionais. Deste modo, o movimento pedagógico da Escola Nova encontrou maior expressão, pelo menos no que respeita aos discursos educativos, devido à circulação de viajantes diversos, contando-se entre eles os professores, que se foram apropriando destas ideias e difundindoas pelos diferentes países de origem.

In what the appeared as an amazing synchronism (what we would perhaps today label as a symptom of globalization) the writings both of the Americans Hall and Dewey, the Brazilian Lourenço Filho, the Europeans Montessori, Decroly, Binet, Kerchensteiner, Claparède, Férrière, Faria de Vasconcelos and Adolfo Lima, among a host of others, established the need for a new school inside of which all the educational tecniques and methods would be adapted to the particular reality of each chid, to his innate laws. (NÓVOA et al., 2003, p. 26).

Também Portugal esteve conectado a este amplo movimento pedagógico através de ligações diversas estabelecidas com os centros de referência pedagógica europeus. Por exemplo, mesmo antes da implementação da $1^{\text {a }}$ República Portuguesa (1910), o Decreto de 29 de maio de 1907 valorizava o conhecimento produzido no estrangeiro e a utilidade que poderia ter para Portugal. Esta peça legal, como afirma Fernandes (1979, p. 11), possibilitou a abertura de "concurso de bolsas de estudo de estudo para a Alemanha, Inglaterra, França, Áustria, Suíça, Bélgica, Suécia e Itália”. A criação desta "corrente de ideias” permitiu incorporar princípios pedagógicos nas instituições de ensino portuguesas enquadrando-se com aquilo que eram caraterísticas de outros sistemas educativos considerados mais avançados.

Fernandes (1979) refere que com a criação das Faculdades de Letras e das Escolas Normais Superiores, decorrentes da reforma educativa republicana, confirmou-se a criação de disciplinas "novas", como a Psicologia Experimental, constituíram-se Laboratórios de investigação, auxiliares da ação pedagógica, e alteraram-se currículos. No que se refere à formação de professores salienta a importância das disposições legais para criarem "um quadro favorável ao refrescamento 
dos processos de formação docente e trouxeram à atividade alguns professores de mérito incontestável” (FERNANDES, 1979, p. 15). Destacando-se, por exemplo, na Escola Normal Primária de Lisboa o curso teórico de psicologia sob a responsabilidade de Alberto Pimentel Filho ou ainda a ação de António Aurélio da Costa Ferreira responsável, em 1919/1920, "por um curso de psicologia experimental destinado aos candidatos a professores primários” (Idem).

A emergência dos saberes "psi" em Portugal ficou a dever-se, em grande medida, à oportunidade de contactar, estabelecer redes de trabalho com centros de investigação pedagógica no estrangeiro e aplicar esses conhecimentos à realidade portuguesa. É este procedimento triangular de atribuir sentido/significado às realidades nacionais a partir de um olhar externalizado que permite a valorização dos enlaces discursivos ou a universalização de ideias pedagógicos (Ó \& Carvalho, 2009; Nóvoa \& Schriewer, 2000). A este propósito destacamos, em particular, a influência pedagógica suíça em Portugal, nomeadamente através dos estudos e experiências de E. Claparède, entre outros, apropriadas pelo professor da Universidade de Coimbra Augusto Joaquim Alves dos Santos, cujo itinerário académico e socioprofissional tomamos como objeto de estudo nos pontos seguintes.

\section{Alves dos Santos (1866-1924): retrato sumário de uma vida}

Augusto Joaquim Alves dos Santos, nasceu em 1866, em Cabração, concelho de Ponte de Lima (Portugal), filho de Manuel Joaquim Rodrigues dos Santos e de Ana Maria Alves Soares. Para lá dos diferentes cargos que Alves dos Santos ocupou no decorrer da sua vida4, seu

\footnotetext{
4 Entre eles, Secretário da Faculdade de Teologia (1902); inspetor da $2^{\mathrm{a}}$ circunscrição escolar primária (1901-1906); inspetor do circulo escolar de Guimarães (1909); vogal interino do Conselho Superior de Instrução pública (1910); diretor da Biblioteca Geral da Universidade de Coimbra (1916-1924); Secretário da Escola Normal Superior (1918-1924); chefe de gabinete do presidente do governo provisório (1911);
} 
percurso ficou marcado por duas balizas temporais: a primeira, desde o momento da sua formação na Universidade de Coimbra até 1910. E a segunda de 1911 até à data da sua morte em 1924. Assumiremos este quadro temporal para desenvolver um pouco mais o itinerário académico e cientifico de Alves dos Santos.

A sua formação académica iniciou-se no Seminário dos Santos Apóstolos S. Pedro e S. Paulo, em Braga, onde frequentou o curso de Teologia e aí foi ordenado presbítero em 1891. Cerca de dois anos mais tarde, procurou a Universidade de Coimbra onde concluiu a licenciatura e obteve o grau de doutor (1900). A partir desse momento, lecionou como lente substituto naquela academia (FERNANDES, 2005). De acordo com Henriques \& Marchão (2016, p. 264) "a sua relação com a Universidade de Coimbra tornar-se-ia permanente. E a sua vida e pensamento educacional cruzam-se de modo indelével com a instituição universitária portuguesa”.

No que respeita à primeira fase da vida profissional deste homem pode ser caraterizada como um período de desenvolvimento do seu pensamento decorrente da sua formação em Teologia e, por outro lado, um conjunto de abordagens relacionadas com as temáticas educativas progressistas. Nesta primeira fase publicou trabalhos como "Concordismo e idealismo" (1900) ou "O problema da origem da família e do matrimónio em face da Bíblia e da sociologia” (1901); no caso das problemáticas educativas, deu à estampa a "Estatística geral da circunscripção escolar de Coimbra, relativa ao anno de 1903-1904" (1906) - decorrente da sua ação enquanto Inspetor Escolar em Coimbra e Guimarães - e "O Ensino Primário em Portugal" (1908). Ao longo da primeira década do século XX evidencia-se uma aproximação crescente, do ponto de vista cronológico, às questões da educação constituindo-se uma preocupação que nunca mais abandonou. Na verdade, em 1908, declarava que a instrução tinha conhecido uma "acidentada existência" (SANTOS, 1908, p. 519). Considerava que apenas depois da Revolução Liberal Portuguesa (1820), com particular destaque para a segunda

presidente da Câmara Municipal de Coimbra (1918-1921); deputado (1919/1921) ou ministro do trabalho (1921-1922). 
metade de oitocentos, embora com muitos avanços e recuos, a instrução primária portuguesa tinha sido colocada no centro das preocupações políticas. É muito claro quando afirma que "o reconhecimento, cada vez mais generalizado de que a instrução é o nosso problema máximo, impulsiona já essa viva campanha, que a iniciativa particular move contra o analfabetismo e do qual devemos necessariamente colher os melhores frutos" (SANTOS, 1908, p. 520).

Defendia, nesta altura, que o ensino primário em Portugal deveria constituir-se como esteio do desenvolvimento do país. Para o efeito, era necessário encontrar as instituições adequadas a alterar o estado em que se encontrava o ensino, apesar dos esforços realizados. Dava como exemplo, a ação política levada a efeito no "segundo ministério da presidência de Hintze Ribeiro" onde se procurou favorecer uma "pedagogia moderna sobre a escola primária" (Idem, p. 516). Efetivamente, Alves dos Santos mostrava a sua concordância com uma formação integral da criança onde fosse possível desenvolver as capacidades intelectuais e físicas (Idem, p. 519). Esta ideia é também corroborada por GARRIDO (1998, p. 337) quando afirma que Alves dos Santos defendia que "o futuro cidadão deveria receber uma educação integral, simbiose da higiene mental, espiritual e física”. Era portanto necessário criar instituições escolares cujo propósito maior fosse construir um novo modelo de sociedade através de uma pedagogia baseada na instrução e na educação cívica e moral dos indivíduos.

Este pensamento encontra maior expressão na segunda fase da sua vida que coincide com a implementação da $1^{\mathrm{a}}$ República Portuguesa (1910-1926). Efetivamente, o regime republicano recolocou a escola no centro da sua ação política e como meio capaz de alcançar o objetivo de construir uma sociedade nova. É do interior deste processo de mudança que decorre a criação das Faculdades de Letras das Universidades de Lisboa e Porto e a substituição da Faculdade de Teologia pela Faculdade de Letras na Universidade de Coimbra (1911). Na Faculdade de Letras da Universidade de Coimbra, Alves dos Santos desempenhou o cargo de professor de Filosofia, História Moderna e Contemporânea e Psicologia Experimental. É relevante assinalar que também esteve associado à 
criação das Escolas Normais Superiores, direcionadas para a formação de professores, onde também haveria de lecionar Psicologia Genética (ABREU, 1991, p. 113).

A $1^{\text {a }}$ República Portuguesa proporcionou a Alves dos Santos um espaço alargado para pensar a educação na perspetiva progressista que antes ele já defendera, do ponto de vista das ideias em, por exemplo, "O ensino primário em Portugal” (1908). Como afirma Fernandes (1993, s.p.) "a secularização do regime político e da mundividência social refletiu-se na orientação cientifica e profissional da plurifacetada personalidade de Alves dos Santos”.

Ao longo da segunda fase temporal que referimos previamente, o seu pensamento pedagógico clarificou-se e aprofundou-se. Entre 1910/11 e 1924 publicou um conjunto de trabalhos científicos de enorme importância. Salientamos, entre outros (1910; 1915; 1916), três obras que consideramos constituírem o fundamento do seu projeto pedagógico: " $\mathrm{O}$ crescimento da criança portuguesa (subsídios para a constituição de uma pedologia nacional)", publicado em Coimbra (1917); "Educação Nova as bases I - o corpo da criança”, publicado no Porto (1919); ou ainda, "Psicologia Experimental e Pedologia (trabalhos, observações e experiências realizadas no laboratório)" publicado em Coimbra (1923). Estes trabalhos inspiraram-se em grande nomes da pedagogia da época que o próprio teve o privilégio de conhecer, contactar e aprender nos seus laboratórios. É sobre esta matéria que o ponto seguinte tratará.

\section{A missão pedagógica ao estrangeiro (Suíça e França): apropriação}

O regime republicano português, logo após a sua implantação (1910), apressou-se a legislar no campo educativo. O decreto de o9 de maio de 1911 criou as Faculdades de Letras, já referidas no ponto anterior, prevendo-se também a constituição de Laboratórios de Psicologia. A Faculdade de Letras da Universidade de Coimbra aprovou uma missão de estudo ao estrangeiro com o objetivo de aprofundar 
"conhecimentos especiais sobre psicologia experimental e, assim, habilitar-se a organizar o primeiro laboratório psicológico do nosso país" (SANTOS, 1913, p. 41). Esta missão recaiu sobre o professor Alves dos Santos que "nos primeiros dias de agosto" de 1912 foi de navio até Marselha, depois de ter parado em Barcelona, com destino principal à cidade de Genebra, na Suíça, onde chegou nos últimos dias do mês de agosto desse ano.

Genebra era considerada como um dos mais notáveis focos de cultura científica ocidental e serviu de palco aos estudos de Alves dos Santos dado que aí podia aprofundar conhecimentos relacionados com a Psicologia junto de atores de reconhecida competência internacional como Edouard Clapàrede que dirigia à época o laboratório psicológico da Universidade de Genebra. Alves dos Santos realçava ainda que além da importância da Universidade de Genebra:

acresce a circunstância de se haver fundado, nesta mesa cidade, um Instituto de Sciências Psicológicas e de Educação, que funciona este ano pela primeira vez e que eu sabia ser destinado a iniciar e a adestrar na prática pedagógica e na técnica das sciências psicológicas experimentais todos quantos, no país, ou no estrangeiro, quisessem preparar-se ou aperfeiçoar-se, segundo os princípios da pedagogia moderna. (SANTOS, 1913, p. 46).

Definidos os princípios desta "missão de estudo" e justificada a escolha de Genebra para aprofundar conhecimentos teóricos e práticos, Alves dos Santos dedicou os primeiros 15 dias de setembro ao estudo relacionado com a organização do sistema educativo suíço, nomeadamente o cantão de Genebra. Simultaneamente, assistiu a várias conferências, das quais o próprio destacou "uma conferência de Mr. Cartaillac sôbre o homem das cavernas e a civilização paleolítica" (SANTOS, 1913, p. 47), outra de M. Godin sobre as problemáticas da puberdade e do crescimento e, por fim, de Madame Sèverine sobre guerra e pacifismo (idem).

Na quinzena seguinte iniciou, após obtida a autorização do reitor, os trabalhos no laboratório de psicologia, embora na ausência de E. Claparède, com auxílio de dois assistentes de laboratório: Marie de Lange 
e Katrasoff que se encontravam na cidade de Genebra. Começou por desenvolver trabalhos de psicologia quantitativa, foi tomando notas e manuseando os aparelhos existentes no Laboratório e continuou a estudar o sistema educativo. Neste período temporal Alves dos Santos (1913, p. 48) referia que teve oportunidade, de realizar algumas experiências, destacando a:

determinação do limiar absoluto e diferencial das sensações (estesiometria e algesimetria); percepção estereognóstica; localizações tácteis; ilusões de pezo e de volume; avaliação das grandezas visuais pelo aparato de Munsterberg; ilusões ópticas; tempos de reacção e de associação (psicocronometria); medida da memória, por vários processos; técnica dos cronoscópios e dos cilindros registadores (cimógrafos); e, finalmente, experiências sôbre esfigmografia e pletismografia.

O professor de Coimbra apropriava-se, deste modo, de um conjunto de saberes e técnicas que mais tarde haveria de utilizar em Portugal. O regresso a Genebra (de viagens ao estrangeiro) de Edouard Claparède imprimiu ainda maior motivação aos estudos levados a efeito por Alves dos Santos. Afirmava ele que a partir de meados de outubro o seu tempo fora repartido entre a Universidade de Genebra e o Instituto Jean-Jacques Rosseau que tinha sido inaugurado há poucos dias (21 de outubro) com um discurso de Claparède.

Na Universidade de Genebra, Alves dos Santos (1913, p. 49) frequentou os cursos de psicologia e pedologia de Cláparede (dez lições) afirmando que adquiriu "uma sôma maior e mais exacta de conhecimentos positivos, do que aquela que me seria possível obter, ao cabo de muitos meses, se os passasse todos a queimar as pestanas, debruçado sôbre a sciência escrita dos tratadistas de psicologia!”. No entanto, a sua passagem por Genebra possibilitou o contacto com outros intelectuais que também ajudaram à fundamentação teórico-prática do seu pensamento pedagógico. Entre outros, destaca Jules Debois (História da Pedagogia); Th. Flournoy (Psicologia e Filosofia das Ciências) ou A. Férrière (Psicologia Genética). 
No Instituto Jean-Jacques Rosseau frequentou vários cursos e teve contacto com autores diversos onde se salientam pela sua importância os seguintes:

Curso do Dr. Paul Godin, laureado do Instituto e da Academia de Medicina, sôbre a evolução do corpo da criança, em sete lições. No dia 24 de outubro, morfologia humana em função de crescimento; no dia 26, crescimento; proporções métricas desde o nascimento até à idade adulta; no dia 28, prática da observação; influências que agem sôbre o crescimento; no dia 31, influência da função de reprodução; puberdade; no dia 2 de novembro, leis do crescimento; no dia 7 , as correlações do crescimento e da individualidade; e, finalmente, no dia 9, relações do crescimento com a inteligência. (SANTOS, 1913, p. $52)$.

Alves dos Santos realça no seu relatório o material didático que encontrou naquele instituto que servia de auxiliar e elemento comparativo durante as sessões que ali decorriam. Depois de cada lição todos os assistentes eram convidados a iniciar-se na "prática antropométrica" e "a comprovar experimentalmente as noções teóricas expendidas pelo professor” (idem). Teve oportunidade ainda de frequentar o curso prático de Maday, sobre inquéritos sociais relativos à infância e o curso teórico-prático de C. de Collet, relacionado com os problemas da voz e a sua importância nas escolas.

Além do contacto estabelecido com um conjunto significativo de intelectuais, a parte final da sua viagem foi ocupada a tentar encontrar material didático que pudesse apetrechar o primeiro Laboratório de Psicologia Experimental em Portugal que haveria de criar em Coimbra logo depois do regresso da sua missão ao estrangeiro. Foi aconselhado a procurar material didático em três casas produtoras: a casa Drosten, em Bruxelas; a casa Zimmerman, em Leipzig; e a casa Peyer \& Favarger, em Neuchatel. Todavia, Alves dos Santos (1913, p. 54) assumiu que "a compra (...) seria mais vantajosa em Paris, na casa Boullite"5, uma vez que já conhecia.

$5 \mathrm{Na}$ sua passagem por Paris teve oportunidade de adquirir os seguintes instrumentos para o seu Laboratório de Psicologia Experimental que fundou na Faculdade de Letras da Universidade de Coimbra: “1) Cilindro registador de Marey,.$^{\circ}{ }^{1}$ 
Reconhecido pelos ensinamentos colhidos na Suíça, em particular a Edouard Claparède, partiu para Paris a 19 de novembro de 1912. Nesta cidade esteve 12 dias. Teve oportunidade para conhecer os laboratórios de fisiologia e de psicologia da Sorbonne onde foi recebido por Piéron. Depois visitou o Museum D' Histoire Naturelle, onde conheceu o Instituto Psicológico e, por fim, visitou o Laboratório Clínico de Neurologia (Salpétrière) e o Laboratório de Pedagogia Normal (Escola Primária de Grange-aux-Belles).

A chegada a Portugal no final desse ano ficou marcada pelo entusiasmo com que tomou para si a iniciativa de criar um Laboratório de Psicologia Experimental à semelhança do que tinha encontrado nos locais visitados. Foi encontrado um espaço provisório - no Instituto de Coimbra (aqui funcionou até 1914, passando depois para a Faculdade de Letras da Universidade de Coimbra) - onde iniciou as suas experiências convicto de que o seu contributo para a construção de uma nova visão pedagógica estava agora melhor fundamentado e, segundo o próprio, desenvolveria as "faculdades de iniciativa e de espontaneidade intelectual" dos seus alunos e dos portugueses, em geral.

\section{Alves dos Santos (1866-1924): por uma pedagogia portuguesa ou ciência pedológica nacional - difusão}

(cimógrafo); 2) folhas de papel para traçados; 3) tinta para envernizar; 4) verniz para fixar os traçados; 5) Vavios de cera para defumar as folhas; 6) dois suportes de Marey, sendo um com excêntrico de Pachon; 7) dois tambores de Marey, modêlo simples; 8) dois, de alavanca, muito sensíveis, modêlo aperfeiçoado; 9) tubos de borracha, com válvula; 10) cronógrafo directo, de Iaquet; n) pneumógrafo de Marey; 12) pletismógrafo de Hallion e Conte; i3) cardiógrafo de Pachon; 14) esfigmógrafo de transmissão, de Marey; 15) ergógrafo completo, de Mosso; 16) cronometro eléctrico de d'Arsonval; 17) pilhas eléctricas e acumuladores; 18) estesiómetro de Michotte, completo, com suporte; 19) mioestesímetro de Toulouse e Vaschide; 20) dinamógrafo de Chéron e Verdin; 21) utensílios para o arranjo dos tambores; 22) aparelhos para identificação antropométrica; 23) oscilómetro de Pachon; 24) reHexómetro clínico de Toulouse e Piéron; 25) martelo de Déjerine; 26) aparelho para o estudo dos tremores da mão;' 27) termómetro de temperatura local, de Peterson; 28) dinamómetro de tracção”. (SANTOS, 1913, p. 56). 
Nas décadas iniciais do século XX, o discurso relacionado com as causas do atraso português tinha sido reforçado fruto de circunstâncias sociais, económicas e políticas. O professor Alves dos Santos considerava que o problema maior encontrava-se na educação e que o sistema político monárquico não tinha conseguido alcançar o desejável progresso do país dado que não soubera colocar "ao centro" as problemáticas educativas, em particular a questão do analfabetismo. Esta ideia é também realçada por Abreu (1991, p. 334-335) quando afirma a propósito do professor Alves dos Santos:

Imbuído desse optimismo lógico e antropológico de matriz iluminista que percorre a amplitude dos seus escritos pedagógicos, evocava a terminologia comtiana para concluir que Portugal se encontrava então numa fase metafisica, quando comparado com os países anglo-saxónicos. O atraso da nossa raça radicar-se-ia no factor educativo, indicador que consubstanciava todos os males da grei, entre eles o atraso das estruturas económicas e a rigidez do tecido social.

A pretensão da $1^{\mathrm{a}}$ República Portuguesa de construir um homem novo encontrou no movimento da educação nova os fundamentos teórico-práticos que colocavam ao alcance do novo regime atingir tal desígnio. A Escola tornara-se um pilar essencial do regime republicano. Neste quadro, Alves dos Santos desenvolveu esforços para afirmar a(s) Ciência(s) da Educação como é percetível pelos estudos que foi desenvolvendo no decorrer do tempo correspondente.

A análise à obra de Alves dos Santos permite-nos identificar uma ideia central defendida pelo professor de Coimbra ao longo da sua vida: a construção de uma ciência pedológica nacional. Alves dos Santos identificou os problemas e defendeu a sua resolução através da instituição escolar e da criação de uma pedagogia portuguesa cientifica. O caminho proposto por Alves dos Santos passava pela valorização da psicologia experimental, resultado das influências suíças, junto dos públicos escolares. Era preciso identificar, medir, classificar para, posteriormente, se poder agir no que respeita a fatores relacionados com, por exemplo, a hereditariedade do sujeito escolar. Defendia que, consoante o meio físico ou social que envolvia a criança, assim se definia 
a sua evolução. Para o efeito era preciso estudar crianças portuguesas para obter dados válidos. É perentório quando referia a impossibilidade de estudar a criança portuguesa de acordo com padrões das crianças estrangeiras:

Esta forma de crescimento [absoluto ou global] é a única que tem sido considerada, entre nós, com a circunstância agravante de se aferirem crianças portuguesas por estalões métricos, que foram organizados sobre bases, fornecidas por mensurações realizadas em crianças estrangeiras! (SANTOS, 1915, p. 177).

Este tipo de conhecimento era impreciso e insuficiente para compreender as "variações" do ser humano. Para o efeito, propunha estudar "o crescimento relativo ou as proporções métricas do corpo da criança, nas idades de evolução, e basear sobre as respetivas mensurações os cânones antropométricos, desde a infância até à idade adulta" (Idem).

As considerações que convocamos para este texto anteriormente, encontravam-se devidamente fundamentadas em autores diversos. Desde logo, Paul Godin, Edouard Claparède ou Stanley Hall. Este conhecimento adveio da sua atualização científica, sobretudo, aprofundada quando realizou a sua missão de estudo à Suíça e França. Alves dos Santos, afirmava que o desenvolvimento deste tipo de conhecimento era fundamental para auxiliar os educadores. É neste sentido que afirmava em 1915:

A primeira parte da tarefa que nos impusemos consiste em coligir, seriar, interpretar e coordenar os referidos elementos [antropométricos], afim de que se torne possível oferecer à puericultura nacional uma tabela de médias, que substitua as tabelas estrangeiras, ainda agora, por nosso mal, usadas, em os nossos estabelecimentos de ensino! (SANTOS, 1915, p. 177).

Esta ideia que se consubstancia na construção de uma ciência pedológica nacional é reforçada em 1919 quando o autor publica o livro "Educação Nova - as bases". Nesta obra, começa por dizer que procura afirmar a constituição de uma pedologia nacional a partir das observações e experiências realizadas por ele "em crianças da nossa 
terra” dado que só assim "se irá organizando uma pedologia portuguesa tam necessária à nossa educação" (SANTOS, Preâmbulo).

Ao longo deste trabalho evidencia-se uma preocupação do autor com aquilo que em Portugal já se tinha produzido sobre esta matéria (realçando trabalhos de Adolfo Coelho, Agostinho de Campos, Virgínia de Castro Almeida, Carneiro de Moura, Faria de Vasconcelos, Palyart Pinto Ferreira, António Sérgio, Mendes Corrêa, Padre António d'Oliveira ou A. Aurélio da Costa Ferreira), mas destaca-se também o conjunto de pedagogos que convoca para dar suporte às suas ideias e, em particular, para valorizar o conhecimento psicológico. São diversas as referências a Compayrè, Claparède, Cellerier, Dubois, Ribot, Davidson ou Dewey, entre muitos outros). Há uma evidente relação entre os conhecimentos de natureza psicológica e os contextos escolares e/ou pedagógicos na sua matriz discursiva.

O conjunto de ideias que procuramos transmitir materializou-se em ações concretas no Laboratório de Psicologia Experimental da Faculdade de Letras da Universidade de Coimbra. Este espaço, fundado pelo próprio, proporcionou a Alves dos Santos um conhecimento maior sobre a criança portuguesa através de observações, relações entre o corpo e a mente, aplicando inquéritos, entre outros aspetos, permitindo-lhe, pelo menos em teoria, ir ao encontro do seu desejo de construir uma ciência pedológica nacional.

Na publicação do seu livro "Psicologia Experimental e Pedologia" (1923) realçava a importância da medida para "determinar o processo de eclosão do fenómeno psíquico; as condições e as circunstâncias em que se produz; o sistema de interdependências que se observam (...) entre o físico e o fisiológico e o moral" (SANTOS, 1923, p. 19).

O que se assistiu ao longo do percurso de Alves dos Santos foi a uma aposta crescente na psicologia como elemento fundamental à pedagogia. Contributo significativo para o processo de cientificidade que era procurado pela pedagogia. Parece-nos claro quando refere:

As vantagens duma pesquisa desta natureza são manifestas; assim como se nos afigura de valor incontroverso o seu alcance cientifico; pois que as conclusões, a que se chegar, interessam à 
higiene, à pedagogia, e até à moral, pelas informações e subsídios, que podem subministrar a estas ciências, em ordem à consecução dos fins que elas têm em vista: o aperfeiçoamento do individuo, pela consolidação das qualidades boas, que possua, e pela extirpação dos vícios, de que enferme. (SANTOS, 1923, p. 101).

Há uma ideia de utilitarismo presente nos discursos de Alves dos Santos uma vez que os seus trabalhos e observações tinham em vista a "qualidade da população" onde se percebe que com uma população com "qualidades boas" torna-se mais fácil de moldar de acordo com os princípios da época que circulavam no interior das instituições escolares suportados pelos discursos científicos apoiados pelo Estado.

Parece evidente que aquilo que mais se procurou, com influências estrangeiras inegáveis, foi a possibilidade de melhor governar os indivíduos identificando aqueles que possuíam aspetos hereditários menos adequados e, deste modo, melhorar a ordem social, pública e garantir o futuro da nação. Eis, portanto, um dos objetivos maiores da denominada Ciência Pedológica nacional, defendida por Alves dos Santos. Era necessário conhecer mais a criança portuguesa, no detalhe, para melhor a governar e construir a nova sociedade defendida pelo regime republicano.

\section{Considerações finais}

A análise do itinerário académico de Alves dos Santos evidencia uma ideia fundamental, associada ao regime republicano, que permite uma compreensão do seu pensamento e ação: a crença na educação como fator de progresso do país. A partir desta ideia, que mesmo antes da implantação da $1^{\text {a }}$ República Portuguesa já defendia, durante toda a sua vida foca-se na possibilidade de construir uma ciência pedológica portuguesa que não fosse "abstracta e universalmente considerada, mas natural e culturalmente situada” (Fernandes, 2005).

Esta ideia ganhou maior consistência científica quando realizou a missão pedagógica à Suíça e França. O contato com sistemas educativos 
considerados mais avançados naquela época criaram em Alves dos Santos uma dinâmica pedagógica focada no objetivo de conhecer mais sobre as crianças portuguesas e com isso auxiliar as instituições escolares, entre outras, a definir melhor como agir junto dos públicos que frequentavam esses espaços. Este projeto de vida correspondeu à necessidade de cientificação da pedagogia. Neste aspeto a psicologia experimental assumiu uma importância central no conhecimento relacionado com a criança portuguesa. O Laboratório de Psicologia Experimental fundado na Universidade de Coimbra por Alves dos Santos, serviu, em grande medida, este propósito.

As suas obras, em particular as publicadas depois da missão de estudo ao estrangeiro, refletem a importância do seu contato com atores pedagógicos de reconhecida competência internacional (caso de Edouard Claparède ou de Paul Godin). São muitas as citações, as referências bibliográficas e as ideias que nos remetem para a sua viagem pedagógica. Alves dos Santos foi um difusor da Escola Nova em Portugal através da valorização do experimentalismo, por via da psicologia, dirigido à pedagogia. Como afirma Garrido (1998, p. 341):

(...) são abundantes nas obras pedagógicas de Alves dos Santos as referências abonatórias sobre a aplicabilidade dos dados da psicologia experimental à prática pedagógica. Esta linha orientadora, se por um lado reflete o pragmatismo e utilitarismo que marcou as primeiras apropriações da psicologia experimental nos intelectuais portugueses, não esconde, por outro, intenções político-ideológicas relacionadas com a ideia republicana de socializar os indivíduos através da educação.

Como se percebe, o quadro político republicano e o movimento da Escola Nova relacionam-se convenientemente. O propósito do regime era a construção de uma sociedade melhor, depurada e regulada, combatendo, logo à partida, entre outros, os problemas da hereditariedade. Percebe-se, assim, a importância de Alves dos Santos e da criação do seu Laboratório de Psicologia Experimental logo no início do regime político. 


\section{Referências}

ABREU, M. V. A criação do primeiro laboratório de psicologia em Portugal: o Laboratório de Psicologia Experimental da Universidade de Coimbra. Universidade(s), História, memória, perspetivas. Congresso História da Universidade $-7^{\circ}$ Centenário Actas, Coimbra, v. II, p. 107132, 1991.

FERNANDES, J. M. Augusto Joaquim Alves dos Santos. In: NÓVOA, A. et. al. Dicionário dos Educadores Portugueses. Lisboa: IIE [ficha 770], 1993.

FERNANDES, R. A pedagogia portuguesa contemporânea. Venda Nova-Amadora: Instituto de Cultura Portuguesa, 1979.

FIGUEIRA, M. H. Um roteiro da Educação Nova em Portugal. Lisboa: Livros Horizonte, 2004.

GARRIDO, A. A utopia pedagógica de Alves dos Santos (Lente republicano: 1866-1924). AAVV. Ensaios em homenagem a Joaquim Ferreira Gomes. Coimbra: Núcleo de Análise e Intervenção Educacional da Faculdade de Psicologia e de Ciências da Educação da Universidade de Coimbra, p. 333-345, 1998.

GONDRA, J. \& MIGNOT, A. C. (org.). Viagens pedagógicas. São Paulo: Cortez Editora, 2007.

GONDRA, J. G. Apresentação. Dossiê: Viagens de educadores, circulação e produção de modelos pedagógicos. Revista Brasileira de História da Educação, n. 22, p. 13-16, 2010.

HENRIQUES, H. \& MARCHÃO, A. Alves dos Santos (1866-1924): influências psicopedagógicas suíças em Portugal nas primeiras décadas do século XX. In: HERNANDEZ DIAZ, J. M (coord.). Influencias suizas en la educación española e iberoamericana. Salamanca: Ediciones Universidad de Salamanca, 2016, p. 261-270.

NÓVOA, A. \& SCHRIEWER, J. (ed.). A difusão mundial da escola. Lisboa: Educa, 2000.

NÓVOA, A. História da Educação. [Relatório apresentado para a obtenção de provas de agregação]. Lisboa: Faculdade de Psicologia e de Ciências da Educação, 1994.

NÓVOA, A. et al. Educational knowledge and its circulation - Historical and comparative approaches of portuguese-speaking countries. Cadernos Prestige. Lisbon: Educa, 2003.

PINTASSILGO, J. Imagens e leituras da Educação Nova em Portugal. Os relatórios de bolseiros portugueses em visita a instituições educativas 
europeias (1907- 1909). In: GONDRA, J. \& MIGNOT, A. C. (org.). Viagens pedagógicas. São Paulo: Cortez Editora, 2007, p. 195 - 216.

PORTUGAL, Ministério da Educação - Instituto de Inovação Educacional, Reformas do Ensino em Portugal - Reforma de 1911. Tomo II - v. I. p. 142-160.

RAMOS DO Ó \& CARVALHO, L. M. Emergência e circulação do conhecimento psicopedagógico moderno (1880-1960). Lisboa: Educa/ Unidade de I\&D de Ciências da Educação, 2009.

RAMOS DO Ó, J. A “criança problema” e o seu governo em Portugal e no Brasil (1880-1960): discursos e práticas. In: RAMOS DO Ó \& CARVALHO, L. M. Emergência e circulação do conhecimento psicopedagógico moderno (1880-1960). Lisboa: Educa/Unidade de I\&D de Ciências da Educação, 2009, p. 15-154.

SILVA, A. L. D. Escritas de viagem, escritas da história: estratégias de legitimação de Rocha Pombo no campo intelectual. (Tese de Doutorado em Educação), Universidade do Estado do Rio de Janeiro, 2012.

\section{Fontes}

SANTOS, A. J. A. Psicologia e Pedologia - uma missão de estudo ao estrangeiro. Revista da Universidade de Coimbra, v. II. Coimbra, p. 4166, 1913.

O crescimento da criança portuguesa (subsídios para a constituição duma pedologia nacional). Boletim Bibliográfico da Biblioteca da Universidade de Coimbra, v. III, Coimbra, p. 173-233; p. 1-60, 1916/1917.

. Psicologia Experimental e Pedologia (trabalhos, observações e experiências realizadas no laboratório). Coimbra: Imprensa da Universidade, 1923.

A medida em Psicologia. Boletim da Biblioteca da Universidade de Coimbra, v. VII (1922-1925), Coimbra, p. 1-25, 1925.

. Laboratório de Psicologia Experimental. Boletim da Biblioteca da Universidade de Coimbra, v. VII (1922-1925). Coimbra, p. 26-41, 1925 .

. O Ensino Primário em Portugal. Notas sobre Portugal, Lisboa, p. 485-520, 1908.

- Elementos de Filosofia Cientifica (de conformidade com o programa oficial. Para uso dos alunos do Ensino Secundário e do Ensino Normal Primário. Coimbra: Moura Marques, 1915. 
. Para a História do Ensino Público em Portugal (um documento importante). Boletim Bibliográfico da Biblioteca da Universidade de Coimbra, v. III, p. 83-113, 1916.

. Educação Nova: as bases: I - o corpo da criança. Lisboa;

Paris: Aillaud; Bertrand, 1919.

Recebido em 12 de março de 2017. Aprovado em 03 de abril de 2017. 